\title{
TRTakadeMi
}

ISSN 2149-9446 | Cilt 06 | Sayı 12 | Mayıs 2021 | Dijital Hayat ve Etik

\section{Ayın Karanlık Yüzü: Yeni Medya ve Etik}

Ayın Karanlık Yüzü: Yeni Medya ve Etik

Mutlu Binark, Günseli Bayraktutan, (2013).

1.Baskı. İstanbul: Kalkedon Yayınları. 168 Sayfa.

ISBN: 978-605-4511-85-3

\section{Gurur Öyküm GÜVEN*}

Dijital temelli olan ve çift yönlü iletişime olanak sağlayan yeni medya, özellikleri itibariyle geleneksel medyadan ayrılmaktadır. Geleneksel medya ve etik konusu uzunca bir süredir ele alınan konulardan olsa da kapsamı yeni medyanın özellikleri ve olanaklarına göre yetersiz kalmaktadır. Bu sebeple "yeni medya ve etik" konusu, yeni bir çalışma alanı olarak karşımıza çıkmaktadır. Etik kavramı çoğu kez ahlak kavramı ile birbirinin yerine kullanılsa da ahlak, "insanların iyi/kötü nitelendirildiği manevi özellikleri, bu özelliklerle sergilediği davranışlar ve huylar" olarak tanımlanabilirken etik, "Insanların davranış ve yargılarını ahlak temelinde inceleyen bir felsefe dalı, ahlak felsefesidir" (İrvan, 2003: 81). Yeni medya etiği ise yeni medya ortamlarındaki sorunlar ve sorumluluklarla ilgili bir kavramdır. Yeni medya ortamlarının artışıla bu ortamlardaki içerik üretimlerinin hızlı ve çok olması, yeni medyanın etik sorunlar bağlamında ele alınmasını zorunlu hâle getirmiştir (Binark ve Bayraktutan, 2013: 25-26). Tüm bu gelişmeler neticesinde incelenen kitap; yeni medya ortamları, içerikleri ve kullanıcılarından kaynaklanan sorunları saptamak ve örneklendirerek olumsuzlukları görünür kılmaktadır.

Incelenen kitapta etik konusu yeni medya perspektifinden ele alınmış, geleneksel medya ve yeni medya etiği arasındaki ilişkilere yer verilmiştir. Eleştirel bir paradigma ile yazılan kitapta, yazarların Türkiye'deki sosyal, politik ve ekonomik değişkenler doğrultusunda örneklendirmeler yaptıkları görülmektedir. Kitap, okuyuculara yeni medya etiği konusunda teorik bilgiler vermekle birlikte pratiğe dayalı çözüm önerileri de sunmaktadır.

* Arş. Gör., İstanbul Ticaret Üniversitesi İletişim Fakültesi, ORCID: 0000-0001-9049-4769, goguven@ticaret.edu.tr. DOI: $10.37679 /$ trta.945288 
Öncelikle "İçindekiler" kısmı incelendiğinde "Ayın Karanlık Yüzü: Yeni Medya ve Etik" adlı kitabın; ön söz, sunuş, giriş, birinci bölüm, ikinci bölüm, üçüncü bölüm, dördüncü bölüm, kaynakça ve eklerden oluştuğu görülmektedir. Toplamda 168 sayfa olan kitapta temel olarak 4 bölüm yer almaktadır:

- I. Bölüm Etik ve Yeni Medya Tartışması

- II. Bölüm Yeni Medya Ortamlarında Etik Sorunlar

- III. Bölüm Yeni Medyada Var Olan Etik Sorunların Nedenleri/Kökenleri ve Sorumlu Tarafları

-IV. Bölüm Sonuç ve Öneriler

Kitap, iletişim etiği alanındaki çalışmalarıyla bilinen Ruhdan Uzun'un etik konusu ve kitapla ilgili değerlendirmelerinin yer aldığı üç sayfalık ön sözle başlamaktadır. Ardından Mutlu Binark ve Günseli Bayraktutan'ın amaçlarını, konunun neden önemli olduğunu, çalışmayı nasıl ve kimlerle gerçekleştirdiklerini açıkladıkları altı sayfalık sunuşla devam etmektedir. Kitabın yazılış amacı "Sunuş" bölümünde, “Amacımız Neydi, Konu Neden Önemli?” başlığı altında (s.12-13) okuyucuya açık bir şekilde aktarılmaktadır. Sosyal medya araç ve ortamlarından doğan etik sorunların kaynağını öğrenmek, bunları tespitlerle örneklendirmek ve yeni dünyanın olumsuzluklarını ifade etmek, kitabın temel amaçlarıdır. Kitap "Yeni Medyada Etik Sorunlar ve İlkeleri Saptamak - TÜBITAK SOBAG 111K328 HIZLI DESTEK PROJESI" başlıklı araştırmanın bir ürünüdür. Projenin, yani aynı zamanda kitabın da hedefleri, şu şekilde sıralanmaktadır (Binark, 2015):

- Yeni medya ortamlarındaki etik sorunların kapsamlı bir şekilde ilk kez bir alan araştırması ile saptamasını yapmak

- Soruna ilişkin olarak farklı tarafların görüşlerine yer vererek siyasi, tarihi, toplumsal ve ekonomik boyutlarıyla konuyu tartışabilmek

- Saha çalışma bulgularına temellenerek yeni medya ortamında olası etik ilkeler için bir çerçeve çizmek

Tüm bunlardan yola çıkılarak proje kapsamında yeni medya profesyonelleri, hukukçu ve iletişimci akademisyenler, kamu kurum ve kuruluşları temsilcileri, konuyla ilgili STK ve meslek örgütü temsilcileriyle görüşmeler yapılmıştır. 64 kişi ile 5 ay süreyle toplam 2620 dakika yapılan görüşmeler sonucunda ortaya koyulan görüşler, incelenen kitabın temelini oluşturmaktadır. Bu sebeple çalışma bir tür "etik üzerine medya etnografisi" olarak tanımlanmaktadır (Binark, 2015: 15).

Kitabın girişinde, yeni medya tanımları yapılarak yeni medya ortamlarını geleneksel 
medyadan ayıran özellikler ortaya koyulmaktadır. Bu özellikler: dijitallik, etkileşimsellik, multimedya biçemselliği, hipermetinsellik, kullanıcı türevli içerik üretim, ara yüzde mevcudiyet hissi, yayılım ve sanallıktır. Ardından "prosumer" yani "üre tüketici" kavramı açıklanarak "Angara Birds, Les Chapulasbles, The Capulcu" gibi dijital oyun örnekleri ile kavram detaylandırılmaktadır. Sıklıkla birbirinin yerine kullanıldığı için öncelikle "ahlak ve etik" kavramlarının tanımı ve ayrımı yapılmış, ardından "iletişim etiği ve yeni medya etiği" kavramları ele alınmıştir. Medya ve etik konusuyla ilgili yapılan diğer çalışmalara atıflarla konuya 21 sayfalık bir giriş yapılmıştır.

Kitabın birinci bölümünde 19 sayfalık "Etik ve Yeni Medya Tartışması” aktarılmaktadır. Yeni medya ortamlarındaki sorun alanları belirlenmiş ve dört kategoride belirlenen görüşmecilerle, görüşme tekniği kullanılarak etiğin kavranılışı üzerine "etiğe yönelik vurgular" belirlenmiştir. Etik kavramının genel algılanışı ardından, etik ve medya tartışmasında yeni bir alan olarak yeni medyaya yönelik bazı kavrayışlar sunulmuştur. Bunlardan bazıları:

- Alanın çok yeni olması; profesyoneller ve sıradan yurttaşların rolünün olması

- Bu alanda yaşanan sorunların kültürel boyutunun önemi

- Yeni medya ortamlarının teknik özelliklerinden özellikle yöndeşmenin tartışma konusu olması

- Yeni medya bireyselliği, yani bir kurum çatısına gerek olmadan içeriklerin üretilmesi

- Yeni medya sorunlarının geleneksel medyanınkinden farklı olduğu

- Yeni medyanın geleneksel medya tarafindan saldırıya uğraması ve mağdur olmasıdır

Kitabın ikinci bölümünde ise "Yeni Medya Ortamlarında Etik Sorunlar" ele alınmaktadır. Bu sorunlara birinci bölümde değinilmiş olsa da (s.39) ikinci bölümde örneklerle ve görüşmecilerin yorumlarıyla sorunlar detaylandırılmıştır. Yeni medya ortamlarında etik sorunlar şu şekilde sıralanmaktadır:

- Özel yaşamın gizliliğinin ihlali

- Telif/patent haklarının ihlali

- İçeriğin asıl kaynağının gösterilememesi sorunu

- Üretilen içeriklerin olgunlaşmadan ve doğruluğunun teyit edilmeden yayılması sorunu

- Kişisel verilerin güvenliğinin sağlanamaması sorunu 
- Veri madenciliği olgusu

- Dijital gözetim olgusu

- Haber ve ticari enformasyonun sınırlarının belirsizleşmesi sorunu

- Yeni medya ortamlarının özellikleriyle kullanıcının yoğun reklama maruz bırakılması sorunu

- İçeriklerin yanıltıcı bir biçimde etiketlenmesi ve başlıklandırılması sorunu

- Nefret söyleminin varlığı

- Bireyin yeni medya ortamında sadece tüketici olarak konumlandırılması sorunu

- Sahadan çıkan diğer sorunlar (anonimlik olgusu, trollük olgusu)

Kitabın üçüncü bölümünde "Yeni Medyada Var Olan Etik Sorunların Nedenleri / Kökenleri ve Sorumlu Tarafları" incelenmiştir. Bu nedenler genel olarak "siyasi, ekonomik ve kültürel nedenler" şeklinde üç başlık altında açıklanmıştır. Yeni medya ortamlarındaki etik sorunlar karşısında alınan tavır ve sorumluluğun tarafları şu şekilde ifade edilebilmektedir:

- Akademisyen (yayınlar ve dersler yoluyla konuya müdahil olma)

- STK temsilcisi (eğitim yoluyla etik bilinç geliştirme)

- STK (suç duyurusu gibi uzun dönemli müdahale, AiHM'e başvurma, kamuya mektup gönderme)

- Yeni Medya Profesyoneli (esnek çalışma biçime karşı, yüz yüze çalışma) (s.125).

Ayrıca yeni medya profesyonellerinin etik konusunu otokontrol mekanizmasıyla ele alması, devletin bir kamu politikası olarak kullanıcıları bilinçlendirmesi (örn. medya okuryazarlığı), herhangi bir kuruma etik ihlal konusunda izleme (monitoring) yetkisinin verilmesi de bu bölümde vurgulanan sorumluluklardandır. Aynı bölümdeki Medya ve Etik Tartışması Yeni Medya Ortamlarını Kapsar mı? Tartışması alt başlığında ortaya çıkan bulgular üç grupta değerlendirilmiştir. İlk grup, yeni medya ortamlarına yönelik ayrı etik ilke ve düzenlemeleri gerekli görürken ikinci grup yeni medya ortamlarına yönelik etik ilke ve düzenlemelerin, geleneksel medyanın ilke ve kuralları kapsamında ele alınabileceği görüşündedir. Üçüncü grup ise hem yeni ilke ve kurallar hem de geleneksel kurallar, yani ikili bir yol önermiştir. Bölümde ortak evrensel değerler vurgusu ve eğitimin gerekliliği yinelenmiştir (s.137). 
Kitabın son bölümü olan Sonuç ve Öneriler kısmında yeni medyada etik sorunların çözümüne yönelik öneriler ve kitapta ele alınan konulara dair çıkarılan sonuçlar sunulmuştur (s.148-159). Etiğin ne olduğuna dair tartş̧maların sürdüğü, etik ve ahlak kavramlarının zaman zaman birbirinin yerine kullanılmaya devam ettiği aktarılmıştır. Yeni medya düzenleyicileri geleneksel medyadan yola çıkarak hareket etmektedir ve bu, eksiklik olarak görülmektedir. Bireylerin eğitimlerle güçlendirilmesi gerekmektedir. Bireyler etik sorunlara müdahale ve mücadelede bulunurken ilişkileri varsa sivil toplum örgütlerini tercih etmektedir. Bireylerin herhangi bir konuda birbirlerine karşı olduğunda sert münakaşalara girdikleri tespit edilmiştir ve bu noktada Türkiye'nin yeni medya ortamındaki tartışma kültürü eksikliği bir kez daha ön plana çıkmaktadır. Bunların temel sebeplerinden biri, anonim kimlikler olarak belirtilmektedir çünkü bu tarz durumlarda empatinin yitirildiği görülmektedir. Esnek çalışma koşulları, çalışma yeri ve arkadaşlara fiziksel uzaklık; etik ve vicdanen esnek olmayı beraberinde getirmekte, bu durum ciddi bir etik sorun yaratmaktadır. Ayrıca, herhangi bir kurumsal çatı altında olmadan yeni medyada içerik üretmenin olanaklı olduğu da yine kitaptan çıkarılan bir diğer sonuçtur.

Kitabın temeli olan projede kullanılan araştırma teknikleri "Durum Saptaması, Betimleyici Çalışma, Literatür Taraması, Derinlemesine Görüşmeler" olarak belirtilmektedir (Binark, 2015). Kitapta görüşme transkriptleri, doküman metinleri, gözlem notları ve probleme ilişkin veriler sunulmaktadır. Bulguların analizi ve yorumlanmasında, çalışmaya katılan görüşmecilerin fikirleri, doğrudan alıntılanarak yapılmıştır. Yapılan analizler sonucunda Yeni Medyada Etik Sorunların Çözümüne Yönelik Öneri ve îlkeler başlığı altında, çeşitli öneriler okuyuculara aktarılmaktadır (s.160-163). Kitabın amacı doğrultusunda kimi durumlarda sayıca fazla ve uzun dipnotlara başvurulmuş olsa da kitap; açık, akıcı ve herhangi bir okuyucu tarafindan anlaşılabilecek bir anlatım diline sahiptir.

Yeni medyada etik konusundaki literatür düşünüldüğünde, çalışmanın etikle ilgilenen farklı alanlardan görüşmecilerle gerçekleştirilmesi, etik sorunların örneklerle tespit edilmesi ve bu sorunlara ilişkin çözüm önerilerinin "çerçeve ve ilkeler" çizilerek ortaya koyulması sebebiyle kitap, literatüre önemli bir katkı sağlamaktadır. Türkiye'de yeni medyaya dair çalışmalar fazlaca yapılmış olsa da "yeni medya ve etik" özelindeki kitap çalışmaları maalesef kısıtlıdır. Mutlu Binark ve Günseli Bayraktutan'ın Ayın Karanlık Yüzü: Yeni Medya ve Etik (2013) adlı kitabı, alandaki öncü çalışmalardandır. Bu kitapta ele alınan "yeni medya ortamlarında farklı biçimlerde üretilen nefret söylemleri" yazarların daha önce kaleme aldıkları Yeni Medyada Nefret Söylemi (2010) adlı eserle ortak paydada buluşmaktadır. Yazar- 
ların bir diğer çalışması olan İletişim Hakkı ve Yeni Medya: Tehditler ve Olanaklar (2019) adlı kitapta incelenen "ifade özgürlüğü hakkı, bilgi edinme hakkı" gibi temel hakların kullanılması da yine bu kitabın konularındandır. Bunlara ek olarak literatürde, Mutlu Binark'ın Hacettepe ve Ankara Üniversitesi Sosyal Bilimler Enstitülerinde yürütülen "Yeni Medya Sosyolojisi" ve "Yeni Medya Araştırmalarında Yöntem ve Teknikler" doktora derslerindeki tartışmaların bir sonucu olarak, Ergin Şafak Dikmen ile derlediği, "Yeni Medya Araştırmalarında Etik Bakış Açısı ve Uygulamalar (2020) adlı bir e-kitap çalışması da karşımıza çıkmaktadır. Yapılan tüm bu çalışmalardan hareketle söylenebilir ki Binark ve Bayraktutan’ın "yeni medya ve etik" konusunu bilimsel etik, hak ve özgürlükler gibi çeşitli alanlarla birlikte ele almaları ve farklı yaklaşımlarla değerlendirmeleri, alana katkılarını önemli ve değerli kılmaktadır.

Değerlendirme yazısına konu edinen kitap, yeni medya ortamlarındaki etik sorunları tespit ederek, bu etik sorunların pratiğine yönelik çözüm önerilerini, konuyla ilgili kişi ve kurumların görüşlerine başvurarak tespit etmektedir. Aynı zamanda bir araştırma projesi olan kitabın, uygun içerikler ve nitelikli kaynaklarla desteklendirildiği görülmektedir. Yeni medya ve etik alanında çalışmalar yapacak akademisyenler için yöntem ve yaklaşım açısından, kitabın ilham verici olduğu söylenebilmektedir.

Kitapta genel olarak etik konusunun Türk toplumu tarafindan göz ardı edilen bir husus olduğu aktarılmaktadır. Çevrim içi etik kurallar, çevrim dışı etik kurallardan bağımsız ve farklı değildir. Bu sebeple kitapta yeni medya alanındaki etik sorunları bilinir kılmak amaçlanmış ve bu sorunlara çözüm önerileri sunulmuştur. Geleceğe yönelik çalışmalarda, bu çözüm önerilerine dair derinlemesine mülakatlar ve anket çalışmalarıyla konu, medya profesyonelleri dışında bir de yeni medyanın kullanıcılarının/tüketicilerinin (kitapta belirtildiği şekliyle "sıradan yurttaş") bakış açısından ele alınabilir, onların çözüm fikirlerine odaklanılabilir. Çalışmanın İstanbul ve Ankara ile sınırlandırılmış olduğu göz önünde bulundurulduğunda, yapılacak yeni çalışmalara sınırlılıklarının genişletilmesi önerilebilir. Kitapta yer alan yeni medya etiğindeki sorunlara yönelik çözüm uygulamaları önerilerine yönelik yapılacak bir çalışmanın da yine yeni medya ve etik alanındaki literatüre katkı sağlayacağı düşünülmektedir. 


\section{Kaynakça}

Akın, A., Kaymak, A., Doğu, B., Aygül, E., Bayraktutan, G., Dirini, I., Binark, M. ve Çomu, T. (2010). Yeni Medyada Nefret Söylemi. İstanbul: Kalkedon Yayınları.

Binark, M. ve Bayraktutan, G. (2013). Ayın Karanlık Yüzü: Yeni Medya ve Etik. İstanbul: Kalkedon Yayınları.

Binark, M. (2015). "Sosyal medya ve Etik 2.0", https://yenimedya.files.wordpress. com/2015/12/hutip-151210.pdf, Erişim Tarihi: 06.12.2020.

Binark, M. ve Dikmen, E. Ş. (2020). Yeni Medya Araştırmalarında Etik Bakış Açısı ve Uygulamalar. Erişim Adresi: https://ekitap.alternatifbilisim.org/pdf/yeni-medya-arastirmalarinda-etik-bakis-acisi.pdf.

Durna, T., Binark, M. ve Bayraktutan, G. (2019). Iletişim Hakkı ve Yeni Medya: Tehditler ve Olanaklar. Ankara: Um:ag Vakfi Yayınları.

İrvan, S. (2003). Medya ve Etik, Medya Etik ve Hukuk, (Der. S. Alankuş), ìstanbul: IPS iletişim Vakfi Yayınları. 


\section{Ayın Karanlık Yüzü: YENI MEDYA UE ETIK}

Mutlu Binark Günseli Bayraktutan

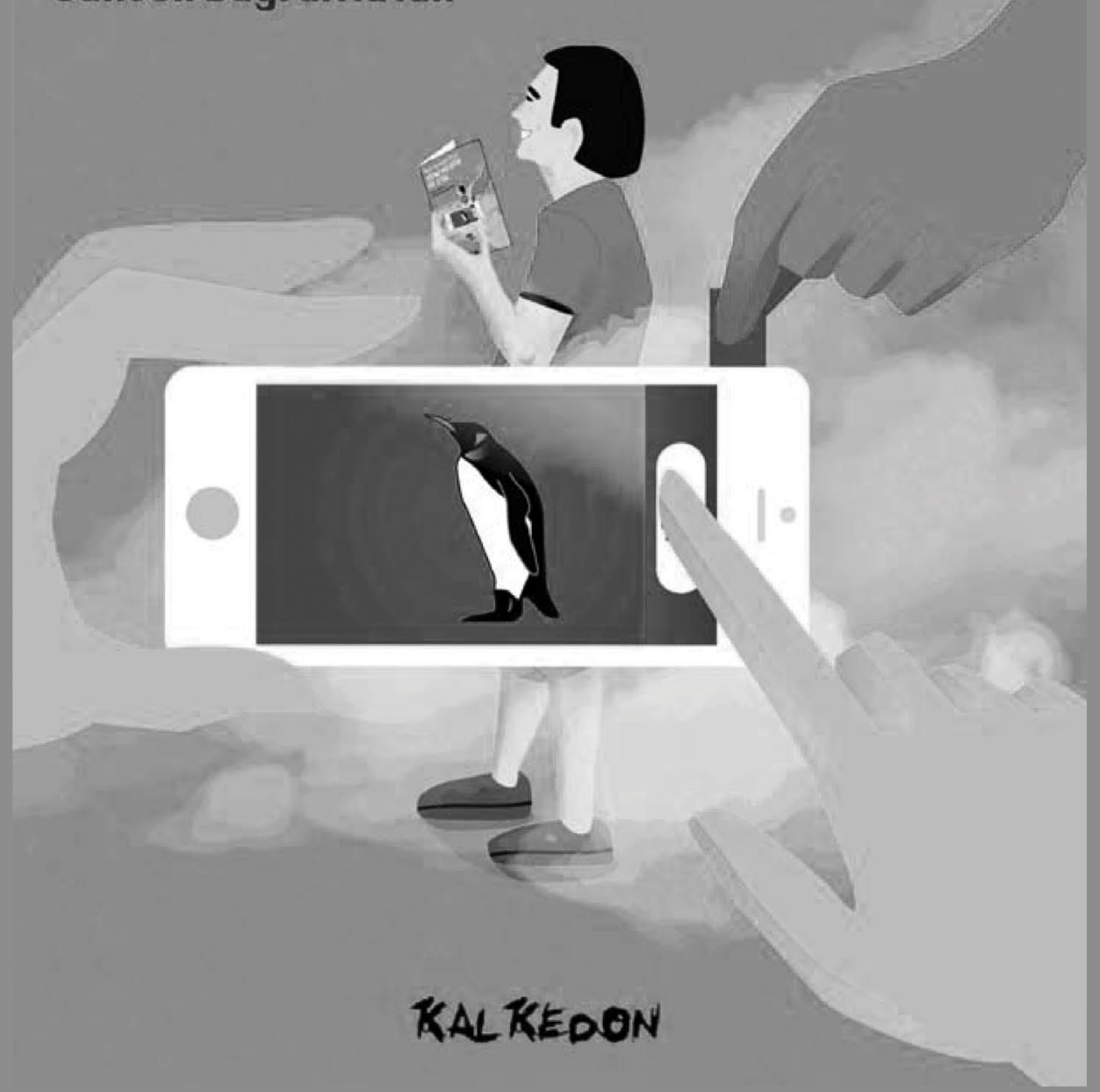

